\title{
Exploring the Impact of Healthcare on Economic Growth in Africa
}

\author{
Juste Somé ${ }^{1}$, Selsah Pasali \& Martin Kaboine ${ }^{3}$ \\ ${ }^{1}$ Department of Economics, Université Norbert Zongo, Koudougou, Burkina Faso \\ ${ }^{2}$ African Center for Gender, United Nations Economic Commission for Africa, Addis Ababa, Ethiopia \\ ${ }^{3}$ Social Development Policy Division, United Nations Economic Commission for Africa, Addis Ababa, Ethiopia \\ Correspondence: Juste Somé, Department of Economics, Université Norbert Zongo, Koudougou, Burkina Faso.
}

Received: March 1, 2019

Accepted: April 1, $2019 \quad$ Available online: April 11, 2019

doi:10.11114/aef.v6i3.4110

URL: https://doi.org/10.11114/aef.v6i3.4110

\begin{abstract}
This paper empirically investigates the relationship between health expenditures, health outcomes and economic growth in Africa using data from 48 African countries over the period 2000-2015 in a panel data regression framework. In line with wider literature on economic growth as well as health economics, the paper first finds that maternal, infant and child mortality rates are all negatively and significantly associated with economic growth in Africa. In addition, life expectancy at birth is positively associated with economic growth. A 9.4-year increase in life expectancy leads to 1 per cent increase in real GDP per capita. Second, the paper finds that health expenditures have direct and indirect effects on economic growth that are positive and economically meaningful. In particular, a 10 per cent increase in health expenditures leads to an increase in annual average real GDP per capita by 0.24 per cent. Third, education emerges as a strong determinant of both economic growth and health outcomes in Africa, particularly when female education is considered. The main policy implication of this paper is that governments should aim at spending more and efficiently on the overall health system to progress over health outcomes and benefit from the positive externalities leading to economic growth. In addition, it is crucial that governments partner with private sector for resource mobilization and effective service delivery.
\end{abstract}

Keywords: health expenditure, health outcomes, economic growth, panel data estimations, Africa

\section{Introducation}

Health is increasingly being recognized across the world as a key aspect of development and economic wellbeing of individuals and nations (Piabuo and Tieguhong, 2017). Indeed, there is widespread consensus in academic and policy circles that apart from being a human right, health leads to significant economic gains (Bloom et al., 2001; and Well, 2007). Health is both a cause and a consequence of economic growth (Amar et al., 1999). There is also evidence for a positive link between health outcomes and economic growth across regions and periods. However, the literature review conducted by this paper failed to identify sufficient cross-country empirical evidence on health-growth nexus in Africa based on recent data and various health measures. Furthermore, existing studies on African have not sufficiently tackled country-specific characteristics. Some cross-country studies that exist such as Kouassi et al. (2018) and Piabuo and Tieguhong (2017) are specific to some subregions of Africa.

This paper empirically examines the relationship between healthcare and economic growth in Africa using a panel data regression framework. The main premise behind this study is that the relationship between healthcare and economic growth can be analyzed through the direct and indirect effects of total health expenditures per capita on changes in real GDP per capita. The paper starts with an investigation of the direct effect of health expenditures on economic growth controlling for standard growth determinants. Next, the paper investigates whether health expenditures have indirect effects on economic growth. We hypothesize that improved health outcomes (reduced maternal, infant and child mortality rates and increased life expectancy) positively and significantly affect economic growth in Africa. We also hypothesize that increased health expenditures significantly improve health outcomes. These hypotheses are tested by compiling data for 48 African countries over the period 2000-2015. Five distinct measures of health are used in this study. First, on the input side, health is measured by total health expenditure per capita which includes domestic government, domestic private and external health expenditures. Second, on the outcome side, health outcomes are measured by infant mortality rate, child mortality rate, maternal mortality rate and adult life expectancy. 
The empirical results of this study point toward a strong positive relationship between health expenditures and economic growth on the one hand and health expenditures and health outcomes on the other hand. The results are largely in line with growth literature as well as health economics literature. There are three sets of empirical results that should be highlighted. First, a 10 per cent increase in health expenditures boosts annual average real GDP per capita by 0.24 per cent. This is an economically meaningful result, given the average annual growth rate in the sample period of 2 per cent. Second, this paper also confirms the long-held view that health matters for economic growth. There is a statistically significant and economically meaningful negative relationship between economic growth on the one hand and maternal and infant/child mortality on the other hand. There is also a positive and significant impact of adult life expectancy on economic growth. Third, this paper confirms that health expenditures are critical for improving health outcomes in Africa.

This paper contributes to the health economics literature in that it provides estimates of the quantitative effects of health expenditure and health outcomes on GDP growth based on the most recent data from Africa while accounting for individual unobserved heterogeneity. The paper is unique in two respects. First, it is one of the very few studies on the relationship between healthcare and economic growth using panel data, which include countries in all the subregions of Africa. Second, the paper differs from others by conducting a more comprehensive analysis of the direct and indirect impacts of health expenditure on economic growth in Africa based on the most recent data.

The structure of the rest of the paper is as follows. Section 2 provides a succinct literature review surrounding the three guiding questions that motivate this paper. Section 3 introduces the empirical methodology used in this paper and highlights its advantages over other strategies tested during research phase. Section 4 introduces the data along with definitions, descriptive statistics and sources. Section 5 presents the empirical results. Section 6 concludes.

\section{Literature Review}

The literature review is structured around recent empirical studies that investigate three critical relationships which guide the empirical questions raised by this study for Africa. This section starts with a review of the relationship between health expenditures and economic growth. It continues with a review of the relationship between health outcomes and economic growth and finally reviews empirical research investigating the impact of health expenditures on health outcomes.

\subsection{Health Expenditures and Economic Growth}

The relationship between public health expenditures and economic growth has been profoundly explored in developing and developed countries. The empirical results generally suggest a positive relationship between health expenditures and economic growth. For instance, Huang et al. (2010) investigate the relationship between per capita real GDP growth and the physical capital, human capital and health investment using provincial data from China in 1978- 2005 period. They find that both health and education have actual compelling effects on economic growth. Gyimah-Brempong and Wilson (2004) investigate the effects of health as human capital on the growth rate of per capita income for 21 Sub-Saharan African countries in 1975-1994 period and for 23 countries of Organization for Economic Co-operation and Development (OECD) 1961-1995 period. According to their results, investment in health human capital, measured by the ratio of health care expenditure to GDP, positively and significantly influences the growth rate of per capita income, after controlling for standard growth determinants.

The direction of causality between health expenditures and economic growth is largely disputed in the literature. Mayer (2001) finds a strong causality from GDP to healthcare expenditures for 18 Latin American countries. Mehrara et al. (2011), test for Granger causality between the health expenditure and the GDP in a panel of 11 selected oil rich developing countries over the 1971-2007 period. The results show a strong causality from oil proceeds and economic growth to health expenditure in the oil rich countries. Yet, in the short- and long-run, GDP is not affected by health spending in any significant manner. Amiri and Ventelou (2012) querythe causal relationshop in OECD countries and conclude that bi-directional Granger causality was predominant.

Other authors go beyond causality tests to consider the cointegration in the relationship between health expenditure and GDP. Elmi and Sadeghi (2012) show that economic growth and health spending have a bilateral causality and long-run relationship in developing countries during the 1990-2009 period. In the same vein, Kouassi et al. (2018), in a panel data analysis for 14 Southern African Development Community (SADC) countries over the period 1995-2012, find that health expenditure and GDP per capita are cointegrated.

\subsection{Health Outcomes and Economic Growth}

Bloom et al. $(2001,2004)$ are among seminal papers that provide strong empirical evidence in favor of health as well as demographic variables in determining economic growth. Using cross-country data over the 1965-1990 period, Bloom et al. (2001) find that a 1\% increase in life expectancy results in an increase in GDP per capita growth rate of over 3\% per year over the period of study. Furthermore, over the same period, over half of the difference in growth rates between 
Africa and the rest of the world is explained by health and demographic variables. Bloom et al. (2004), using panel data for 1960-1990 period at 10-year frequency discover that health outcomes have positive and statistically significant effects on economic growth. Specifically, a one-year enhancement in life expectancy leads to a $4 \%$ rise in output shown by increased labor productivity.

Amiri and Gerdtham (2013) query how maternal and child health affect economic growth and vice versa using data from 170 countries over the 1990-2010 period. They find that there is a bidirectional causality between maternal and child health and GDP, with a stronger causality running from maternal and child health to GDP. Usman et al. (2015) examine the long run relationship between health and economic growth in Nigeria over the 1961-2012 period. They find a long-run relationship between health, as measured by life expectancy and crude death rate measures, and economic growth. Further tests using the Granger causality test, show a one directional causality running from health as measured by life expectancy and crude death rate to economic growth. Haung et al. (2010) investigate the effect of HIV/AIDS on life expectancy, human capital investment choices and income growth in 38 African countries between 1980 and 2004. They find that HIV/AIDS had led into a considerable decline in life expectancy in African countries, which has then led to lower educational attainment and slower economic growth. Other scholars (Kimani-Murage, 2013; Bain et al, 2013) explore the effects of other negative shocks like malnutrition in children. According to Bain et al. (2013) 54\% of deaths in children in African countries in 2001 were related to malnutrition. They argue that malnourished children start their lives at a suboptimal level which is a serious developmental concern.

Unlike the studies above, Acemoglu et al. (2007), by using panel data from 59 countries from 1940 to 1980, does not confirm that a large increase in life expectancy leads to an increase in per capita income. They argue that raised life expectancy boosts population, which originally decreases capital-to-labor and land-to-labor ratios, hence reducing the per capita income. This happens when factors of production such as land are supplied inelastically.

\subsection{Healthcare Expenditures on Health Outcomes}

There is a bourgeoning literature that examines the relationship between health expenditures and health outcomes including maternal mortality, infant mortality, under-five mortality and life expectancy at birth. The results found thus far are largely mixed and insufficient to provide a strong positive relationship. For example, Filmer et al. (1999) present empirical evidence using cross-national data from 104 countries investigating the effect on child- and infant mortality by both non-health factors and public expenditures. Their results show no impact of public spending on health outcomes. The discrepancy between the definite and supposed potential of public spending is outlined by three possible explanations, including the allocation of public spending, the net impact of additional public supply, and public sector efficacy.

However, others provide evidence of strong relationship between health expenditures and health outcomes. Using a panel of 45 African countries between 1995 and 2011, Novignon and Lawanson (2017) find that a 10 per cent increase in health expenditure per capita leads to a reduction of infant mortality by 1.1 deaths per 1,000 live births and a reduction of 1.5 deaths per 1,000 live births in under-five mortality. In addition, public health expenditures have relatively more significant impact than private health expenditure. The findings also suggest that health expenditures have significant longer term effects on child health. Baldacci et al. (2004) adopting panel data from 120 developing countries in the 1975-2000 period, find that education and health capital are positively and significantly affected by expenditure on both education and health and therefore can lead to higher economic growth. For instance, an increase in health spending-to-GDP ratio by $1 \%$ is associated with a rise in the under- 5 child survival rate of $0.2 \%$ and an increase of $0.5 \%$ in annual per capita GDP growth, on average, in developing countries. Bein et al. (2017) examine the relationship between total healthcare and health outcomes for eight East African countries over the 2000-2014 period. They find that an increase in healthcare expenditures by 10 per cent is associated with a reduction in the number of infant deaths, number of under-five deaths and number of neonatal deaths by 5.4, 6.6 and 2.9, respectively. In the same vein, Anyanwu and Erhijakpor (2007), using panel data from 47 African countries for the period of 1999-2004, find that health expenditures significantly reduce infant and under-five mortality rates.

A critical portion of health expenditures depends on external sources. Focusing on health aid and its impact on health outcomes, Mishra and Newhouse (2009) examin the association between health aid and infant mortality using panel data of 118 countries covering the period of 1973-2004. They found that health aid had a benign and statistically significant impact on infant mortality. In particular, growing per capita health aid by 2 times is correlated with a 2 per cent decrease in the infant mortality rate.

\section{Methodology}

The primary objective of this study is to investigate the relationship between economic growth and health in a panel data growth regression framework using aggregate data from 48 African countries over the period between 2000 and 2015. This sectioon first focuses on the estimation of the effect of health expenditure and health outcomes on GDP 
growth based on most recent data from Africa while accounting for individual unobserved heterogeneity.

The empirical model on the relationship between health and economic growth employed in this study is closely related to Bloom et al. (2001), Acemoglu et al. (2019) and Piabuo and Tieguhong (2017). The model can be derived from the standard growth model, augmented by other inputs of interest in the aggregate production function. The main inputs in the standard growth model include investment ratio (a proxy for saving rate) and human capital. Human capital consists of education and health. The endogenous growth models highlight the importance of human capital with particular attention to education and skills. The empirical model considered here implies that health as a component of human capital is also an important determinant of economic growth (Bleakley, 2010).

Growth equations are used in line with Ordinary Least Squares (OLS) estimation in cross section analyses (Barro, 1991; Mankiw et al., 1992). However, the country-specific effect is ignored in a cross-section regression. This country-specific effect is often correlated with other explanatory variables in empirical models thereby creating omitted variable bias and obscuring a causal relationship. In response to criticisms about the fact that OLS estimation leads to biased estimates, Islam (1995) proposed the use of Fixed Effects (FE) model, also known as Least Square Dummy Variables (LSDV), within a panel data framework in order to control for the individual specific effects such as country characteristics, which are time invariant. This estimation method was earlier used in Acemoglu et al. (2019). More precisely, we consider the following fixed effects growth model:

$$
Y_{c, t}=\gamma . Y_{c, t-1}+\beta . \text { Health }_{c, t}+\theta . X_{c, t}+\alpha_{c}+\varepsilon_{c, t}
$$

The dependent variable $Y_{c, t}$ is the log real GDP per capita in constant 2010 US dollars and Health ${ }_{c, t}$ represent the explanatory variables of interest which are either health expenditures, i.e.the log of total health expenditure per capita)and health outcomes such as maternal mortality rate, infant mortality rate, under-five mortality rate and adult life expectancy. $X_{c, t}$ represents a vector of control variables that potentially affect economic growth, including investment-to-GDP ratio, trade openness, education, i.e. mean years of schooling, consumer price index inflation, and global index of governance. Note that investment-to-GDP ratio enters in the regression as the average value of current and previous period. Subscripts $c$ and $t$ are country and time indicators. $\alpha_{c}$ is a full set of country fixed effects which absorbs the impact of any time-invariant country specific characteristics. The error term $\varepsilon_{c, t}$ includes all other time-varying unobservable shocks to GDP per capita.

The presence of a lagged dependent variable on the regressors could make LSDV/FE an inconsistent estimator when the time dimension $\mathrm{T}$ is small. ${ }^{\mathrm{i}}$ However, as noted by Alvarez and Arellano (2003), and Acemoglu et al. (2019), the LSDV/FE estimator performs better when the variance in unobserved heterogeneity,i.e. the variance in country-specific effect, $\sigma_{\alpha}$, is large relative to the variance of the error term in the model, $\sigma_{\epsilon}$. Given the importance of unobserved heterogeneity as confirmed by the relative variance (see Table 3 ) and given that the panel dimension $(\mathrm{N}=48)$ is large relative to the moderate length of the sample period $(\mathrm{T}=16)$ in this study, the preferred estimation method is the fixed effects (FE) model. The preferred estimation method in this study is also the one used by Acemoglu et al. (2019) to obtain their benchmark results.

The secondary objective of this paper is to examine the impact of health expenditures on health outcomes. We therefore estimate the equation below again using the fixed effects estimator in panel data context.

$$
\text { Health Outcomes } c, t=\beta \text {. Health Expenditures } c, t+\theta . X_{c, t}+\alpha_{c}+\varepsilon_{c, t}
$$

Health outcomes again are measured by the same four indicators used above while health expenditures similarly represent total health expenditures per capita in country $\mathrm{c}$ and time t. In estimating the above equation, a smaller set of control variables is used and stacked in $\mathrm{X}$ including mean years of education completed among population age 15 and above and governance. We also use mean years of primary schooling for women over age 15 in an alternative specification. Note that this alternative specification is estimated for a panel of 37 African countries in years 2000, 2005, 2010 and 2015, which yields 4 data points for each country in the data set. This is due to the fact that data on mean years of primary schooling for women over age 15 are available only for these years in the sample. Note that real GDP per capita is highly correlated with health expenditure per capita which leads to its exclusion as explanatory variable for health outcomes.

Before presenting the empirical results, it is important to note that establishing causal effects is beyond the scope of this paper. While the paper relies on existing and rigorous growth regression frameworks both in terms of variables and panel data estimators, the results are not free from biases emanating from several endogeneity concerns. First, omitted

\footnotetext{
${ }^{\mathrm{i}}$ The bias in the LSDV/FE estimation of the effect of lagged dependent variable, on the order of 1/T, goes to zero as T becomes larger. Standard LSDV/FE model with the lagged dependent variable is appropriate when T is large (see Islam
} (1995) and Beck and Katz (1995)). 
variable bias is likely to influence our results as country-specific unobserved time-variant factors are not fully accounted. Fixed effects only account for country-specific unobserved time-invariant factors. In addition, reverse causality could affect the relationship between health outcomes and expenditures on the one hand and economic growth on the other. As such, our results presented in the next section should be interpreted with caution.

An alternative method to the standard fixed effects is instrumental variables (IV) estimation. However, finding appropriate instruments that will be correlated with the included explanatory variables of the model and yet uncorrelated with error term is not straightforward. Internal lagged variables are often used as instruments. However, this has the inconvenience of drastically reducing the number of observations in the estimation when there are irregular data gaps, as it is the case in this study. Given these constraints, the paper opts out from this estimation method. Future research will survey the literature for potential instruments and test for their validity in capturing the exogenous variation in the variables of interest. Moreover, the choice of the estimation method in this study is also supported by the work of Binder et al. (2005) and Bun and Windmeijer (2010) who show that the variance and the bias of IV estimators, including General Method of Moments (GMM) estimator, crucially depend on the ratio of the variances of the individual specific effects and the idiosyncratic errors, $\sigma_{\alpha} / \sigma_{\epsilon}$. Indeed, Binder et al. (2005) show that the asymptotic variance of the difference GMM estimator is increasing with the variance of the individual-specific effects, $\sigma_{\alpha}$. While Bun and Windmeijer (2010) show that the bias of the IV estimators, including GMM estimators, is an increasing function of relative variance $\sigma_{\alpha} / \sigma_{\epsilon}$.

\section{Data}

One of the main contributions of this empirical study is its exclusive focus on entire Africa with most recent data. Data availability is however a binding constraint. While data are available for several African countries reaching a total of 48 countries, not all have data for a long period of time. As such, the compiled data set is an unbalanced panel. In addition, the main variable of interest of this study, namely total health expenditures per capita is available only for the period of 2000-2015. Table A1 in appendix describes the main variables used.

Table 1. Summary Statistics (2000-2015)

\begin{tabular}{llllll}
\hline Variables & Obs. & Mean & Std. Dev & Min & Max \\
\hline Log difference of real GDP per capita & 768 & 2.02 & 6.98 & -97.35 & 80.19 \\
Maternal mortality ratio (deaths per 100,000 live births) & 768 & 545.35 & 345.58 & 9 & 2,650 \\
Infant mortality ratio (deaths per 1,000 live births) & 758 & 48.25 & 84.33 & 0 & 565 \\
Under-five mortality ratio (deaths per 1,000 live births) & 758 & 73.88 & 132.86 & 0 & 929 \\
Life expectancy at birth & 768 & 58.22 & 7.75 & 39.8 & 76.2 \\
\hline Log of current health expenditure per capita & 754 & 390.73 & 106.77 & 150.16 & 639.25 \\
\hline Investment ratio (per cent) & 724 & 21.67 & 11.4 & 1.10 & 145.75 \\
Mean years of schooling & 751 & 4.63 & 1.99 & 1.1 & 10.3 \\
Trade openness (per cent) & 750 & 76.72 & 38.11 & 19.10 & 351.11 \\
Inflation rate (per cent) & 728 & 7.15 & 12.47 & -10.31 & 181.47 \\
Index of governance (-100 to 100) & 768 & -25.43 & 23.30 & -77.17 & 35.2 \\
Resource-Rich countries & 768 & - & - & 0 & 1 \\
\hline
\end{tabular}

World Development Indicators Database maintained by the World Bank is the main source of data for all variables except health data. World Health Organization (WHO) database is preferred for health outcomes and total health expenditures. Specifically, in this paper health expenditures are measured by current health expenditures in constant 2010 US dollars which include domestic government, domestic private and external health expenditures. Finally, data compiled by Barro and Lee (2013) is used to proxy education with years of schooling. Table 1 above provides simple summary statistics for the variables used in all regressions. Note that the full sample includes 768 observations for 48 countries over 16 years. Investment ratio, a critical variable in growth regressions records the largest number of missing observations.

Guided by the empirical questions raised in this study and in line with the wider econometric literature, there are two main dependent variables to investigate. First, there is economic growth measured by the logarithmic difference of GDP per capitai ${ }^{\text {ii }}$ in constant 2010 US dollars from one year to the next and multiplied by 100. As shown in Table 1 above, this yields an annual average growth rate of 2 per cent in Africa with substantial variation across the sample countries

\footnotetext{
ii In addition to real GDP per capita, labor productivity measured by real GDP per worker was used as an alternative dependent variable. Results are qualitatively and quantitatively identical.
} 
and period. Growth volatility in oil producing and fragile countries explain this large variation, e.g. Libya in post-2010 period along with Equatorial Guinea. Looking at the change in real GDP per capita from 2000 to 2015, African countries grew by 42 per cent on average, which increased on average their GDP per capita from $\$ 1,781$ in 2000 to $\$ 2,458$ in 2015. Indeed, there is large variation across the continent where for instance GDP per capita more than doubled in Equatorial Guinea, Ethiopia, Rwanda, Angola and Chad, while it stagnated in Burundi and the Gambia and declined by more than 20 per cent in Libya, Zimbabwe and Central African Republic.

Second, the paper focuses on health outcomes which are measured by maternal mortality ratio, infant mortality ratio, under-five mortality ratio as well as adult life expectancy at birth. On average, for 48 African countries over the 2000-2015 period, maternal mortality ratio was on average 545 deaths per 100,000 live births. This high average is largely driven by Sierra Leone, Liberia and Chad, particularly in early 2000s. Next, over the same period, infant mortality rate and under-five mortality rate in Africa were on average 48 and 74 deaths per 1,000 live births respectively. During the period, infant mortality rate, which is highly sensitive to immunization coverage, decreased by almost 97 deaths per 1,000 live births. As for the under-5 mortality rate, which accounts for factors beyond immunization coverage, there has been also progress with an average decline of 25 deaths per 1,000 live births from 2000 to 2015 . Finally, there is adult life expectancy at birth in Africa which averaged 58 years over 2000 to 2015. It increased by over 8 years from 2000 to 2015 with largest progress being observed in Rwanda with a 21-year increase.

Moving to the right-hand side of the empirical specification, the main variable of interest in this study is health expenditures measured by current health expenditure per capita in constant 2010 US dollars. Table 2 below lists the countries that make up the core sample of the study, together with the average health expenditures per capita over the 2000-2015 period. The current health expenditures include domestic general government health expenditures, domestic private health expenditures and external health expenditures. The empirical analysis of this paper does not discriminate between financing sources, as the objective is to see whether health expenditures in their entirety have any impact on economic growth. Future research will identify which one of the three financing sources matter the most, as there are different policy implications with each source. The average health expenditure per capita in Africa was USD 90 during the sample period. There is a large variation from the Democratic Republic of Congo recording the minimum at USD 12 to South Africa and Namibia recording USD 390. Exploiting the longitudinal dimension of the data, the average increase in health expenditure per capita from 2000 to 2015 across 48 countries is 222 per cent with a maximum of 889 per cent in Liberia, i.e. from USD 7 to USD 69, and a minimum of 7 per cent in Democratic Republic of Congo, i.e. from USD 18.4 to USD 19.7 In regression analysis, this proxy also enters the equation in a logarithmic form to ease interpretation.

Finally, and following the seminal papers in economic growth literature as referred earlier, Table 1 also reports summary statistics on critical control variables including investment rate, education, trade openness, inflation and governance. Cross-country and panel regressions for economic growth consistently find statistically significant impact of these variables on economic growth. Theoretically, capital accumulation, education, trade openness and inflation are all proximate causes of economic growth while governance measures institutional quality which is a deeper determinant of growth. Governance is measured by the World Governance Index and thus accounts for all dimensions of governance including voice and accountability, control of corruption and government effectiveness, among others. Except for inflation, all these control variables are expected to have positive impact on economic growth as widely established in high-quality academic literature. Last but not least, we also control for resource endowment in the growth equation by including a resource rich-dummy. Resource rich countries in the sample are those with 20 per cent or more of their exports in either oil or minerals. Based on this measure, of the 48 countries, 29 were considered resource-rich in 2000 against 33 in 2015. iii Controlling for this variable is critical in African context given the share of primary products in exports and volatility in commodity prices.

iii Data on international trade from UNCTAD database online have been used. Statistical Note has the following: (SITC 33 for oil and SITC $27+28+32+34+35+68+667+971$ for minerals). 
Table 2. Health expenditures for countries in the core sample

\begin{tabular}{llllll}
\hline Country & $\begin{array}{l}\text { Health } \\
\text { Expenditure } \\
\text { per capita }\end{array}$ & Country & $\begin{array}{l}\text { Health } \\
\text { Expenditure } \\
\text { per capita }\end{array}$ & Country & $\begin{array}{l}\text { Health } \\
\text { Expenditure } \\
\text { per capita }\end{array}$ \\
\hline Angola & 85 & Ghana & 62 & Namibia & 389 \\
Burundi & 17 & Guinea & 19 & Niger & 19 \\
Benin & 28 & Gambia & 26 & Nigeria & 63 \\
Burkina Faso & 25 & Guinea-Bissau & 30 & Rwanda & 37 \\
Botswana & 321 & Equatorial Guinea & 198 & Sudan & 77 \\
CAR & 15 & Kenya & 44 & Senegal & 37 \\
Cote d'Ivoire & 60 & Liberia & 27 & Sierra Leone & 46 \\
Cameroon & 50 & Libya & 265 & Eswatini & 191 \\
Congo, Dem. Rep. & 12 & Lesotho & 66 & Chad & 31 \\
Congo, Rep. & 44 & Morocco & 128 & Togo & 23 \\
Comoros & 62 & Madagascar & 18 & Tunisia & 208 \\
Cabo Verde & 121 & Mali & 29 & Tanzania & 30 \\
Algeria & 186 & Mozambique & 22 & Uganda & 41 \\
Egypt & 97 & Mauritania & 37 & South Africa & 392 \\
Ethiopia & 13 & Mauritius & 291 & Zambia & 54 \\
Gabon & 208 & Malawi & 24 & Zimbabwe & 77 \\
\hline
\end{tabular}

Note: This table lists the countries that make up the core sample of the study, together with the average over the period 2000-2015 of health expenditures per capita in constant 2010 USD.

\section{Estimation Results and Discussion}

This section presents empirical results pertaining to the three guiding questions that this paper examined. First, Table 3 reports regression results from growth regressions where health expenditures and health outcomes appear as the key variables of interest through five specifications where each variable enters one by one. Second, Table 4 reports the impact of health expenditures on health outcomes with a narrower set of covariates. Post-estimation results are reported at the bottom panel. These final sets of results have been subject to a variety of robustness checks including the addition of various control variables, alternate use of time dummies, treatment of outliers and use of alternative dependent variables.

The top panel of Table 3 clearly indicates that health matters for economic growth both with respect to inputs and outcomes. First, there is a significant positive relationship between health expenditures and economic growth such that a 1 per cent increase in total health expenditure per capita raises economic growth by 0.024 per cent. Given sample characteristics of health expenditures per capita however, a 1 per cent increase is negligible as the median increase in health expenditures over 16-year period is over 160 per cent. Given the estimate in Table 3, around 40 per cent of increase in health expenditure per capita is sufficient to increase real GDP per capita by 1 per cent over the sample period. Alternatively, this economically meaningful result can be highlighted by the following example. If the Gambia, who is around the first quartile of the health expenditure per capita distribution, would increase its current health expenditure per capita to the level found in Egypt, who is around the third quartile of the distribution, then real GDP per capita would have increased by $3.6 \%$ on average over the sample period of 16 years. The implication for the Gambia would be to increase its health expenditure per capita from $\$ 26.5$ to $\$ 97.4$, which is the amount Egypt spends on average in the sample period. While this is a substantial requirement, the Gambia has managed to raise its health expenditure per capita from $\$ 15$ to $\$ 35$ over the sample period.

Second, health outcomes matter for economic growth. Starting with maternal mortality ratio, which is measured by maternal deaths per 100,000 live births, a one-unit decrease in maternal mortality implies a 0.008 per cent increase in real GDP per capita. In other words, if maternal mortality ratio were to be reduced by 125 deaths, then GDP per capita would have increased by 1 per cent. The following example can highlight the importance of this result. Moving from the maternal mortality rate of Gabon, i.e. 348 deaths per 100,000 live births, to that of Cameroon, i.e. 691 maternal deaths per 100,000 live births, reduces real GDP per capita growth by $2.4 \%$ over the sample period. Note that the maternal mortality rate has dropped in Cameroon from 750 maternal deaths to 596 over the sample period. 
Child and infant mortality rates are also negatively and significantly associated with economic growth. Specifically, a one-unit decrease in infant (child) mortality would increase real GDP per capita by $0.05(0.02)$ per cent. It is interesting to see that infant mortality has a larger impact both in terms of magnitude and statistical significance since it largely relates to immunization coverage while child mortality measures the health system with a wider perspective.

Finally, Table 3 shows a positive and statistically significant impact of life expectancy on economic growth. As noted earlier, this health outcome appears in economic growth regressions very frequently with a statistically significant positive coefficient. The same result applies to Africa in the recent sample period. Specifically, a 1-year increase in adult life expectancy increases real GDP per capita by 0.106 per cent implying that a 9.4-year increase could lead to a 1 per cent increase in real GDP per capita. Alternatively, if Cameroon could increase its average adult life expectancy at birth from approximately 54 years to the level observed in Comoros, i.e. 61 years, then Cameroon's real GDP per capita would grow by 1.2 per cent.

The next panel in Table 3 presents the estimation results of growth covariates. Note that all covariates enter with the expected sign. The impact of education on economic growth is very large at above 1.5 per cent for each additional year of schooling. Surprisingly, investment-to-GDP ratio does not enter significantly even though capital accumulation is a first-order growth determinant. Note that preliminary results were also insignificant for the contemporaneous impact of investment-to-GDP ratio on economic growth but when an average of current and preceding time was used, the regression results turned positive and statistically significant. Table 3 presents results from a later specification where outliers are controlled for in which case the impact of investment on growth turned insignificant. Trade openness, governance and inflation have the expected signs as well as the dummy for resource rich countries. Lagged real GDP per capita enters very strongly and positively implying a strong autocorrelation from one year to the next in the movement of GDP. Post estimation results show a strong fit for the entire model with a high F-statistic and the relative variance between country specific effects and residuals favoring the former and justifying the use of the fixed effects estimator over other panel data methodologies.

The estimation results in Table 3 are overall in line with the wider literature on economic growth as well as health economics. In particular, they are consistent with the findings of Kouassi et al. (2018) and Piabuo and Tieguhong (2017) that there is a long run positive relationship between health expenditures and economic growth for countries in the Economic Community of Central African States (ECCAS) subregion and for countries in the Southern African Development Community (SADC), respectively. The results also confirm the findings in the literature that health outcomes matter for economic growth. In particular, our results are in line with the finding of Bloom et al. (2004) that an increase in life expectancy accelerate GDP per capita growth. In the same vein, Bloom et al. (2005) find that life expectancy is positively associated with labor productivity. Moreover, our results confirm the key finding of Amiri and Gerdtham (2013) that maternal and child health matter for economic growth.

Moving to the last guiding question that motivated this study, Tables 4 and 5 presents the empirical results for each of the four health outcome indicators. The main difference between the two tables is that different measures are used for education. While Table 4 utilizes mean years of schooling, which covers 48 countries, Table 5 utilizes average years of primary schooling for women, which only covers 37 countries. In addition, the latter indicator is available only for 2000 , 2005 and 2010 reducing the sample size drastically. Since female education is a critical factor in explaining maternal and child health, Table 5 is also presented below.

Focusing on empirical results, Table 4 above shows a strong negative relationship between mortality ratios and current health expenditure per capita as well as a strong and positive relationship between health expenditures and adult life expectancy. They are highly statistically significant but also economically meaningful. A 1 per cent increase in health expenditure per capita reduces maternal mortality by more than 1 maternal death. It would take around 36 per cent increase in health expenditure per capita to lower infant mortality by 1 infant death. Finally, it would take 16 per cent increase in health expenditure per capita to reduce child mortality rate by 1 child death. Alternatively, increasing health expenditure per capita from the level observed in the Gambia at the first quartile of the distribution to the level observed in Egypt at the third quartile implies a reduction of maternal mortality ratio by approximately 194 deaths; a reduction of infant mortality ratio by 4.1 deaths and a reduction of 8.9 deaths in child mortality ratio. Given sample averages of 545 , 48 and 73 for the mortality ratios, the reductions reported above are substantial. On the positive side, the same increase in health expenditure per capita leads to additional 3.6 years in adult life expectancy at birth. Note that given sample average of 58.2 years of adult expectancy, additional 3.6 years is substantial. Consequently, in addition to the observed direct impact of health expenditures on economic growth, Table 4 also implies an indirect effect of health expenditures on growth through health outcomes. 
Table 3. Economic Growth, Health Expenditures and Health Outcomes in Africa

\begin{tabular}{|c|c|c|c|c|c|}
\hline & 1 & 2 & 3 & 4 & 5 \\
\hline Log Health expenditure per capita & $\begin{array}{l}0.024 * * * \\
(0.006)\end{array}$ & & & & \\
\hline Maternal mortality ratio & & $\begin{array}{l}-0.008 * * * \\
(0.002)\end{array}$ & & & \\
\hline Infant mortality ratio & & & $\begin{array}{l}-0.047 * * \\
(0.022)\end{array}$ & & \\
\hline Under-five mortality ratio & & & & $\begin{array}{l}-0.022 * \\
(0.011)\end{array}$ & \\
\hline Life expectancy at birth & & & & & $\begin{array}{l}0.106 * * \\
(0.050)\end{array}$ \\
\hline Log real GDP per capita (t-1) & $\begin{array}{l}0.843 * * * \\
(0.016)\end{array}$ & $\begin{array}{l}0.855 * * * \\
(0.018)\end{array}$ & $\begin{array}{l}0.876 * * * \\
(0.015)\end{array}$ & $\begin{array}{l}0.876 * * * \\
(0.015)\end{array}$ & $\begin{array}{l}0.872 * * * \\
(0.017)\end{array}$ \\
\hline Investment ratio & $\begin{array}{l}0.02 \\
(0.034)\end{array}$ & $\begin{array}{l}0.008 \\
(0.034)\end{array}$ & $\begin{array}{l}0.022 \\
(0.037)\end{array}$ & $\begin{array}{l}0.02 \\
(0.038)\end{array}$ & $\begin{array}{l}0.021 \\
(0.036)\end{array}$ \\
\hline Mean years of schooling & $\begin{array}{l}1.197 * * * \\
(0.385)\end{array}$ & $\begin{array}{l}1.824 * * * \\
(0.368)\end{array}$ & $\begin{array}{l}1.972 * * * \\
(0.356)\end{array}$ & $\begin{array}{l}1.967 * * * \\
(0.358)\end{array}$ & $\begin{array}{l}1.798 * * * \\
(0.356)\end{array}$ \\
\hline Trade openness ( $\%$ of GDP) & $\begin{array}{l}0.026 * * * \\
(0.009)\end{array}$ & $\begin{array}{l}0.023 * * * \\
(0.009)\end{array}$ & $\begin{array}{l}0.019 * * \\
(0.009)\end{array}$ & $\begin{array}{l}0.019 * * \\
(0.009)\end{array}$ & $\begin{array}{l}0.019 * * \\
(0.008)\end{array}$ \\
\hline Inflation rate & $\begin{array}{l}-0.052 * * * \\
(0.012)\end{array}$ & $\begin{array}{l}-0.047 * * * \\
(0.015)\end{array}$ & $\begin{array}{l}-0.055^{* * *} \\
(0.018)\end{array}$ & $\begin{array}{l}-0.052^{* * *} \\
(0.019)\end{array}$ & $\begin{array}{l}-0.050 * * * \\
(0.016)\end{array}$ \\
\hline Index of governance & $\begin{array}{l}0.101 * * * \\
(0.026)\end{array}$ & $\begin{array}{l}0.092 * * * \\
(0.029)\end{array}$ & $\begin{array}{l}0.095 * * * \\
(0.026)\end{array}$ & $\begin{array}{l}0.098 * * * \\
(0.026)\end{array}$ & $\begin{array}{l}0.093 * * * \\
(0.026)\end{array}$ \\
\hline Dummy for Resource-Rich countries & $\begin{array}{l}0.908^{*} \\
(0.485)\end{array}$ & $\begin{array}{l}0.876 \\
(0.545)\end{array}$ & $\begin{array}{l}1.062 * * \\
(0.500)\end{array}$ & $\begin{array}{l}1.054 * * \\
(0.500)\end{array}$ & $\begin{array}{l}1.017 * \\
(0.507)\end{array}$ \\
\hline Countries $\backslash$ Observations & $48 \backslash 659$ & $48 \backslash 659$ & $48 \backslash 659$ & $48 \backslash 659$ & $48 \backslash 659$ \\
\hline R-squared within & 0.96 & 0.95 & 0.95 & 0.95 & 0.95 \\
\hline F-statistic $\backslash p$-value & $2069 \backslash 00$ & $1257 \backslash 00$ & $1624 \backslash 00$ & $1618 \backslash 00$ & $1542 \backslash 00$ \\
\hline Relative variance $\sigma_{\alpha} / \sigma_{\epsilon}$ & 20.73 & 17.5 & 15.45 & 14.71 & 14.75 \\
\hline
\end{tabular}

Notes: *** $(* *)(*)$ denotes significance at the 1 (5) (10) percent level. Robust standard errors in parentheses are clustered at the country level. Dependent variable is log real GDP per capita. Outliers, defined by observations with standardized residuals $>1.96$ and Cook's Distance $>4 / \mathrm{NT}$, have been excluded in the final estimation.

Table 5 replicates Table 4 but in doing so exchanges mean years of schooling for all with mean years of primary schooling of females. The impact of female education on health outcomes is much stronger and lowers the impact of health expenditures on maternal mortality. Overall, the higher is the years of primary schooling of women, the lower the mortality ratios and the higher the life expectancy. Specifically, a one-year increase in primary schooling of women reduces maternal mortality by approximately 96 deaths. Given the average maternal mortality ratio of 545 maternal deaths per 100,000 live births, this $18 \%$ reduction is substantial. Female education clearly matters for the other three health outcome indicators. A one-year increase in female schooling in primary education leads to 3.3 fewer infant deaths, 8.6 fewer child deaths and 5.2 more years of expected life. There is also a strong relationship between good governance and maternal mortality ratio as well as life expectancy. It is interesting to note that compared to Table 4 , governance matters more in Table 5 when female years of primary schooling is taken into account. This result however is also likely to be driven by the large change in the sample. 
Table 4. Health Expenditures and Health Outcomes in Africa

\begin{tabular}{lllll}
\hline & $\begin{array}{l}\text { Maternal } \\
\text { mortality ratio }\end{array}$ & $\begin{array}{l}\text { Infant mortality } \\
\text { ratio }\end{array}$ & $\begin{array}{l}\text { Under-five } \\
\text { mortality ratio }\end{array}$ & $\begin{array}{l}\text { Life expectancy at } \\
\text { birth }\end{array}$ \\
\hline Log Health expenditure per capita & $-1.328^{* * *}$ & $-0.028^{*}$ & $-0.061^{* *}$ & $0.036^{* * *}$ \\
& $(0.143)$ & $(0.014)$ & $(0.028)$ & $(0.005)$ \\
Mean years of schooling & -25.695 & $-3.329^{* *}$ & $-7.689^{* *}$ & $2.590^{* * *}$ \\
& $(16.617)$ & $(1.588)$ & $(2.977)$ & $(0.621)$ \\
Index of governance & -1.866 & -0.029 & -0.000 & $0.066^{* *}$ \\
& $(1.177)$ & $(0.067)$ & $(0.115)$ & $(0.029)$ \\
\hline Countries\Observations & $48 \backslash 722$ & $48 \backslash 723$ & $48 \backslash 724$ & $48 \backslash 723$ \\
R-squared within & 0.61 & 0.21 & 0.26 & 0.69 \\
F-statistic & $35.78 \backslash 0.00$ & $6.12 \backslash 0.00$ & $8.46 \backslash 0.00$ & $51.33 \backslash 0.00$ \\
\hline Nalue & & &
\end{tabular}

Notes: $* * *(* *)(*)$ denotes significance at the $1(5)(10)$ percent level. Robust standard errors in parentheses are clustered at the country level. Outliers, defined by observations with standardized residuals $>1.96$ and Cook's Distance $>4 / \mathrm{NT}$, have been excluded in the final estimation.

The findings in tables 4 and 5 shed light on the importance of health expenditures on health outcomes in Africa. These findings are in line with those of Bien et al. (2017) and Anyanwu and Erhijakpor (2007). They also show however that there are other indicators that equally if not more matter for health outcomes. For instance, female education plays a critical role in reducing maternal mortality ratio in Africa.

Table 5. Health Expenditures, Female Education and Health Outcomes in Africa

\begin{tabular}{lllll}
\hline & Maternal & Infant & Under-five & Life \\
\hline Log Health expenditure per capita & $-0.848^{* * *}$ & $-0.039^{* * *}$ & $-0.065^{* * *}$ & $0.021^{* * *}$ \\
& $(0.176)$ & $(0.010)$ & $(0.019)$ & $(0.006)$ \\
Average years of primary schooling age 15+ female & $-95.825^{* * *}$ & $-3.277^{*}$ & $-8.660^{* * *}$ & $5.210^{* * *}$ \\
& $(29.479)$ & $(1.724)$ & $(3.068)$ & $(0.921)$ \\
Index of governance & $-4.634^{* * *}$ & -0.024 & -0.054 & $0.121^{* * *}$ \\
& $(1.334)$ & $(0.070)$ & $(0.120)$ & $(0.029)$ \\
\hline Countries $\backslash$ Observations & $37 \backslash 107$ & $37 \backslash 107$ & $37 \backslash 107$ & $37 \backslash 107$ \\
R-squared within & 0.65 & 0.43 & 0.46 & 0.75 \\
F-statistic $\backslash$-value & $21.68 \backslash 0.00$ & $9.64 \backslash 0.00$ & $11.11 \backslash 0.00$ & $45.41 \backslash 0.00$ \\
\hline
\end{tabular}

Notes: $* * *(* *)(*)$ denotes significance at the $1(5)(10)$ percent level. Robust standard errors in parentheses are clustered at the country level. Outliers, defined by observations with standardized residuals $>1.96$ and Cook's Distance $>4 / \mathrm{NT}$, have been excluded in the final estimation.

\section{Conclusion}

Using a panel of 48 African countries over the 2000-2015 period, this paper estimates the impact of (i) health expenditures on economic growth, (ii) health outcomes on economic growth and (iii) health expenditures on health outcomes. While the first two sets of results are concerned with direct impacts of health inputs and health outcomes on growth, the latter is concerned with the indirect impact of health expenditures on growth through health outcomes. The main contribution of this paper is its exclusive focus on Africa based on most recent data covering as many African countries as possible.

The empirical results found in this paper are in line with the wider health economics literature. First, health expenditures have a direct positive impact on economic growth in Africa during the sample period. Second, health outcomes have direct and positive impact on economic growth. Reducing maternal mortality, infant mortality and child mortality are all growth friendly. Finally, the results shed light on the importance of health expenditures on health outcomes in Africa. They however also show that there are other determinants of economic growth that matter equally if not more.

The main policy implication of the findings from this study is that African governments must pay attention to improved health outcomes both as an end goal and as means to economic growth. First, raising health expenditures however is one policy tool and it requires extensive domestic resource mobilization in addition to external financing. Given the 
substantial changes observed in health expenditures per capita across Africa in the 2000-2015 period, it is wise for governments to spend more but efficiently on healthcare to improve the health outcomes that they lag the most and that has significant direct impact on economic growth. Second, since most African countries are still lagging behind in female education, governments should also pay more attention in reducing gender gaps in quality and quantity of education. Indeed, our results suggest that female education in particular is a strong determinant both for economic growth and for maternal and infant mortality reduction.

The results in this study do not discriminate between sources of financing health expenditure. For instance, the measure used for health expenditures in this study includes non-governmental health expenditures as well. Future research can shed more light on differential impacts of health expenditures by financing source. In addition, the results reflect the quantity of spending rather than the quality of spending. Future research in this area could also clarify this qualification. Finally, future research could improve the identification strategy to ensure causal interpretation of the three sets of results.

\section{Acknowledgments}

This research work was carried out to support the Economic Report on Africa (ERA): Healthcare and Economic Growth in Africa of the United Nations Economic Commission for Africa (ECA). The authors are grateful to the team of the ERA, and particularly to Saurabh Sinha, Adrian Gauci, Mama Keita and Hopestone Kayiska Chavula, for valuable comments and advice. The views expressed in this paper are those of the authors and do not necessary reflect those of ECA. The authors declare that they have no competing interests.

\section{Appendix A}

Table A1. Description of the main variables in the dataset

\begin{tabular}{|c|c|}
\hline Description & Data Source \\
\hline GDP per capita (constant USD) & World Bank \\
\hline Gross fixed capital formation ( $\%$ of GDP) & World Bank \\
\hline Trade openness (\% of GDP) & World Bank \\
\hline Consumer price index $(2010=100)$ & World Bank \\
\hline Mean years of schooling & UNDP/Barro-Lee \\
\hline Average years of primary schooling age $15+$ females & World Bank/Barro-Lee \\
\hline Voice and Accountability & World Bank \\
\hline Political Stability & World Bank \\
\hline Government Effectiveness & World Bank \\
\hline Regulatory Quality & World Bank \\
\hline Rule of Law & World Bank \\
\hline Control of Corruption & World Bank \\
\hline Current Health Expenditure (CHE) per Capita in constant (2010) USD & WHO \\
\hline Infant mortality ratio (infant deaths per 1,000 live births) & WHO \\
\hline Under-five mortality ratio (under-five deaths per 1,000 live births) & WHO \\
\hline Maternal mortality ratio (maternal deaths per 100,000 live births) & WHO/World Bank \\
\hline Life expectancy at births (years) & WHO \\
\hline Dummy for Resource-Rich countries (exports of either oil or minerals >=20\%) & UNCTAD/Authors \\
\hline Log of real GDP per capita $=100 * \log ($ GDP per capita in constant 2010 USD) & Authors \\
\hline Inflation rate (in percent $)=100 *(\log$ difference of CPI $)$ & Authors \\
\hline $\begin{array}{l}\text { Log of Health expenditure per capita }=100 * \log \text { (Current Health Expenditure (CHE) per } \\
\text { Capita in constant (2010) USD) }\end{array}$ & Authors \\
\hline $\begin{array}{l}\text { Governance indicator }=\text { simple average of the six governance indicators (rescaled } \\
\text { between }-100 \text { and 100) }\end{array}$ & Authors \\
\hline $\begin{array}{l}\text { Regression Sample: countries with at least one complete observation for the model's } \\
\text { baseline variables }\end{array}$ & Authors \\
\hline
\end{tabular}




\section{References}

Acemoglu, D., \& Johnson, S. (2007). Disease and development: the effect of life expectancy on economic growth. Journal of political Economy, 115(6), 925-985. https://doi.org/10.1086/529000

Acemoglu, D., Naidu, S., Restrepo, P., \& Robinson, J. A. (2019). Democracy does cause growth. Journal of Political Economy, 127(1), 000-000. https://doi.org/10.1086/700936

Alvarez, J., \& Arellano, M. (2003). The time series and cross-section asymptotics of dynamic panel data estimators. Econometrica, 71(4), 1121-1159. https://doi.org/10.1111/1468-0262.00441

Amiri, A., \& Gerdtham, U. G. (2013). Impact of Maternal and Child Health on Economic Growth: New Evidence Based Granger Causality and DEA Analysis. Newborn and Child Health, Study Commissioned by the Partnership for Maternal, Lund University, Sweden.

Amiri, A., \& Ventelou, B. (2012). Granger causality between total expenditure on health and GDP in OECD: Evidence from the Toda-Yamamoto approach. Economics Letters, 116(3), 541-544. https://doi.org/10.1016/j.econlet.2012.04.040

Anyanwu, J. C., \& Erhijakpor, A. E. (2009). Health expenditures and health outcomes in Africa. African Development Review, 21(2), 400-433. https://doi.org/10.1111/j.1467-8268.2009.00215.x

Bain et al. (2013). Malnutrition in Sub-Saharan Africa: burden, causes and prospects. Pan African Medical Journal, 15(1). https://doi.org/10.11604/pamj.2013.15.120.2535

Baldacci, M. E., Cui, Q., Clements, M. B. J., \& Gupta, M. S. (2004). Social spending, human capital, and growth in developing countries: Implications for achieving the MDGs (No. 4-217). International Monetary Fund. https://doi.org/10.5089/9781451875140.001

Barro, R. J. (1991). Economic growth in a cross section of countries. The quarterly journal of economics, 106(2), 407-443. https://doi.org/10.2307/2937943

Barro, R. J., \& Lee, J. W. (2013). A new data set of educational attainment in the world, 1950-2010. Journal of development economics, 104, 184-198. https://doi.org/10.1016/j.jdeveco.2012.10.001

Beck, N., \& Katz, J. N. (1995). What to do (and not to do) with time-series cross-section data. American political science review, 89(3), 634-647. https://doi.org/10.2307/2082979

Bein, M. A., Unlucan, D., Olowu, G., \& Kalifa, W. (2017). Healthcare spending and health outcomes: evidence from selected East African countries. African health sciences, 17(1), 247-254. https://doi.org/10.4314/ahs.v17i1.30

Binder, M., Hsiao, C., \& Pesaran, M. H. (2005). Estimation and inference in short panel vector autoregressions with unit roots and cointegration. Econometric Theory, 21(4), 795-837. https://doi.org/10.1017/S0266466605050413

Bleakley, H. (2010). Health, human capital, and development. Annu. Rev. Econ., 2(1), 283-310. https://doi.org/10.1146/annurev.economics.102308.124436

Bloom, D. E., Canning, D., \& Sevilla, J. (2001). The effect of health on economic growth: theory and evidence (No. w8587). National Bureau of Economic Research. https://doi.org/10.3386/w8587

Bloom, D. E., Canning, D., \& Sevilla, J. (2004). The effect of health on economic growth: a production function approach. World development, 32(1), 1-13. https://doi.org/10.1016/j.worlddev.2003.07.002

Bun, M. J., \& Windmeijer, F. (2010). The weak instrument problem of the system GMM estimator in dynamic panel data models. The Econometrics Journal, 13(1), 95-126. https://doi.org/10.1111/j.1368-423X.2009.00299.x

Elmi, Z. M., \& Sadeghi, S. (2012). Health care expenditures and economic growth in developing countries: panel co-integration and causality. Middle-East Journal of Scientific Research, 12(1), 88-91.

Filmer, D. (1999). Child mortality and public spending on health: how much does money matter?. The World Bank. https://doi.org/10.1596/1813-9450-1864

Gyimah-Brempong, K., \& Wilson, M. (2004). Health human capital and economic growth in Sub-Saharan African and OECD countries. The Quarterly Review of Economics and Finance, 44(2), 296-320. https://doi.org/10.1016/j.qref.2003.07.002

Huang, R., Fulginiti, L. E., Wesley, F., \& Peterson, E. (2010). Health and growth: causality through education. China Agricultural Economic Review, 2(3), 321-344. https://doi.org/10.1108/17561371011078444

Islam, N. (1995). Growth empirics: a panel data approach. The Quarterly Journal of Economics, 110(4), 1127-1170. https://doi.org/10.2307/2946651 
Kimani-Murage, E. W. (2013). Exploring the paradox: double burden of malnutrition in rural South Africa. Global health action, 6(1), 19249. https://doi.org/10.3402/gha.v6i0.19249

Kouassi, E., Akinkugbe, O., Kutlo, N. O., \& Brou, J. B. (2018). Health expenditure and growth dynamics in the SADC region: Evidence from non-stationary panel data with cross section dependence and unobserved heterogeneity. International journal of health economics and management, 18(1), 47-66. https://doi.org/10.1007/s10754-017-9223-y

Mankiw, N. G., Romer, D., \& Weil, D. N. (1992). A contribution to the empirics of economic growth. The quarterly journal of economics, 107(2), 407-437. https://doi.org/10.2307/2118477

Mayer, D. (2001). The long-term impact of health on economic growth in Latin America. World development, 29(6), 1025-1033. https://doi.org/10.1016/S0305-750X(01)00026-2

Mehrara, M., \& Musai, M. (2011). Granger causality between health and economic growth in oil exporting countries. Interdisciplinary Journal of Research in Business, 1(8), 103-108.

Mishra, P., \& Newhouse, D. (2009). Does health aid matter?. Journal of health economics, 28(4), 855-872. https://doi.org/10.1016/j.jhealeco.2009.05.004

Novignon, J., \& Lawanson, A. O. (2017). Health expenditure and child health outcomes in Sub-Saharan Africa. African Review of Economics and Finance, 9(1), 96-121.

Piabuo, S. M., \& Tieguhong, J. C. (2017). Health expenditure and economic growth-a review of the literature and an analysis between the economic community for central African states (CEMAC) and selected African countries. Health economics review, 7(1), 23. https://doi.org/10.1186/s13561-017-0159-1

Usman, H. M., Muktar, M., \& Inuwa, N. (2015). Health Outcomes and Economic Growth Nexus: Testing for Long Run Relationship and Causal Links in Nigeria. International Journal of Economics and Empirical Research (IJEER), 3(4), 176-183.

Well, D. N. (2007). Accounting for the effect of health on economic growth. The quarterly journal of economics, 122(3), 1265-1306. https://doi.org/10.1162/qjec.122.3.1265

\section{Copyrights}

Copyright for this article is retained by the author(s), with first publication rights granted to the journal.

This is an open-access article distributed under the terms and conditions of the Creative Commons Attribution license which permits unrestricted use, distribution, and reproduction in any medium, provided the original work is properly cited 